This year, 230 individuals, including Javier Garcia Martinez, were selected from a pool of almost 5000 candidates.

"I am honored that the World Economic Forum has chosen me as a Young Global Leader out of thousands of highly qualified individuals," said Javier Garcia Martinez. "I am excited to be a part of such an outstanding community of young leaders that share my passion to work towards a better global future."

In 2005, Javier cofounded Rive Technology, Inc., to commercialize the technology that he developed

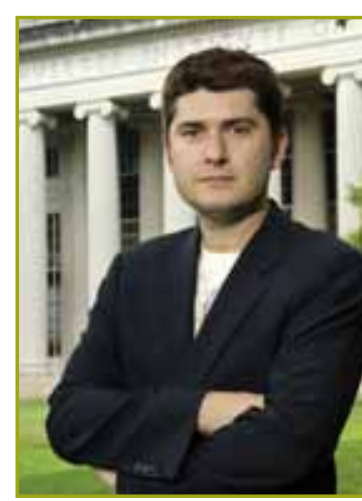

Javier Garcia Martinez during his post-doctoral stay at MIT. The technology is a proprietary method of modifying the pore structure of a zeolite, making it more accessible to larger molecules in a feedstock. Rive selectively introduces mesopores (pores nearly four nanometers in diameter) into a zeolite, allowing larger molecules to access the zeolite and get "cracked" into valuable products. As a result, petroleum refiners obtain a higher yield of desirable products such as gasoline, diesel fuel, and propylene, and less of undesirable products like heavy cycle oil and coke. Rive was recently honored with AlwaysOn's GoingGreen East 50 award for the disruptive potential of its catalyst technology as a cleantech solution.

Javier received his $\mathrm{BS}, \mathrm{MS}$, and Ph.D. in chemistry at the University of Alicante, Spain, where he currently leads the Laboratory of Molecular Nanotechnology.

www.weforum.org

www.rivetechnology.com

\section{Deliang Chen Takes the Helm at ICSU}

\section{rofessor Chen will provide critical leadership as ICSU moves into the exciting second stage of its Strategic Plan 2006-2011.}

On 1 February 2009, Deliang Chen became executive director of ICSU, a non-governmental organization with a global membership of national scientific bodies representing 136 countries. In announcing the news, ICSU President Catherine Bréchignac said "This appointment reflects ICSU's commitment to strengthening international science for the benefit of society. [Chen] brings with him a wealth of expertise, as a leader and an academic, at a key point in ICSU's evolution."

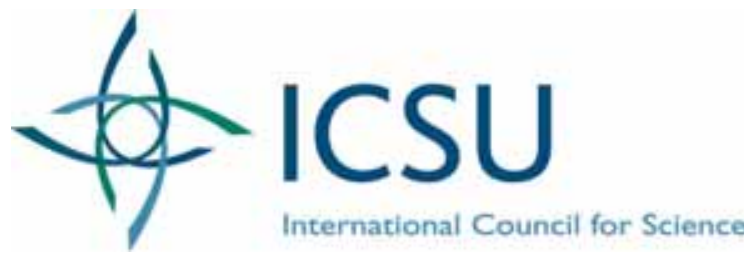

Chen is an internationally renowned climate researcher and is currently a professor of Physical Meteorology and the August Röhss Professor of Physical Geography at the University of Gothenburg in Sweden. He completed his Ph.D. under the guidance of Nobel Prize winner Paul Crutzen, before joining the University of Gothenburg in 1993, where he became a full professor in 2000-at the age of 38. His research interests include regional climate change and variability in Sweden and China, climate dynamics, air pollution, and geostatistics. He is a prolific author with more than 100 peer-reviewed scientific publications, including contributions to the Assessment Report of the Intergovernmental Panel on Climate Change, and has served as an editor on many leading journals.

"I am very excited at the prospect of leading ICSU as it continues to be one of the world's foremost organizations for science," said Chen, "and I look forward to expanding ICSU's activities with integration and interaction among different disciplines, young scientists, and the developing world."

Chen replaces Thomas Rosswall who is retiring after seven years at the helm.

\section{About ICSU}

Founded in 1931, ICSU is frequently called upon to speak on behalf of the global scientific community and to act as an advisor in matters ranging from the environment to conduct in science. ICSU's activities focus on three areas: planning and coordinating research; science for policy; and strengthening the Universality of Science. IUPAC is a member of ICSU.

\section{www.icsu.org}

